\title{
Study on the net profit of Replacing Coal by Electricity based on the strategy of critical electricity price
}

\author{
Wei Zheng ${ }^{1, a}$, Qianqian Chong ${ }^{2, ~ a}$, Xiyuan $\mathrm{Li}^{1, b}$ and Hongfeng Ma ${ }^{1, \mathrm{c}}$ \\ ${ }^{1}$ Liaoning Energy Saving Service Co., Ltd. Shenyang 115000, China; \\ ${ }^{2}$ School of Electrical Engineering Department, Northeastern University, Shenyang 110819, China.

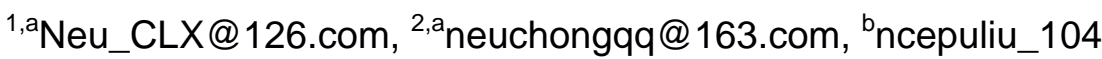 \\ @163.com, 'sdu_xlq@yeah.net@yeah.com
}

Keywords: Critical electricity price; Replacing Coal by Electricity; Peak load shifting.

\begin{abstract}
In order to make Replacing Coal by Electricity (RCE) get better promotion, firstly, a benefit model which based on the benefits of the participators of electric heat storage boiler (EHSB), i.e. grid enterprise, residents and government, was constructed. Secondly, this paper proposed the concept of critical electricity price, and put emphasis on the analysis of the implementation of the critical power price strategy and the idea of the peak clipping, which provided an effective method for the promotion of RCE. Finally, through the example of a certain area implemented with electric boiler and the critical price strategy to obtain the benefits of empirical value.
\end{abstract}

\section{Introduction}

The problem of energy crisis has become seriously, so the researchers all over the world are actively exploring this problem and has developed new environmental and economical heating mode, such as EHSB etc.. The EHSB can make the most of low power storage energy and reduce emissions of pollution gases in the city [1].

Extant literatures have done some research on this aspect. The reference [2] proposed an electric boiler operation mode and economic analysis models, but it didn't consider the critical electricity price. The reference [3] developed the model of electric storage hot water system with economic technical analysis, but the quantitative description was not given. The reference [4] evaluated the overall efficiency of solar water heater systems, and mainly considered environmental benefits, but it didn't consider the benefit of grid enterprise and government.

In view of the above problems, the paper established the benefit model of participating parties based on the participators of power grid enterprise, residents and government's benefits model and presented the concept of critical price. Also the paper used an example to verify the feasibility of the benefit model, and calculated the critical electricity price.

\section{The Concept of Critical electricity Price}

Due to the large of the initial investment of electric boiler, in the study of the cost of electricity heating system,we must consider the government subsidies. And if there haven't government's subsidies, the investment of heating enterprise would be very large, which will not be conducive to the promotion of RCE. And this paper defined the concept of critical price as when the interests of the participants, i.e. grid enterprise, residents and government, reach the maximum value at the same time, and the value of the electricity price is the critical price.

\section{Benefit analysis of critical electricity price}

\subsection{Benefit model of government.}

Considered from a long-term perspective, the implementation of EHSB will reduce the government's investment. In order to calculate the benefits of these quantitative calculations, this study uses the full resource analysis method to carry out the social cost benefit analysis[5]. 
Based on the above theory, the government revenue model is:

$$
\begin{aligned}
M_{g o v}= & \sum_{i=1}^{n} \frac{1}{(1+r)^{i}}\left(R_{M, i}+R_{I, i}+R_{L, i}+R_{A, i}+R_{E, i}\right) \\
& -\sum_{i=1}^{n} \frac{1}{(1+r)^{i}}\left(\Delta V_{i} R_{Q, i}+\Delta P_{i} \theta_{i}+\delta_{i}\right) \\
R_{M, i}= & \sum_{i=1}^{n}\left(P_{S}^{i} \cdot R_{G, S}^{i} T_{S}^{i}+P_{V}^{i} \cdot R_{G, V}^{i} T_{V}^{i}+P_{F}^{i} \cdot R_{G, F}^{i} T_{F}^{i}\right) .
\end{aligned}
$$

Where: $M_{\text {gov }}$ is the government's overall benefit of implementing RCE for $\mathrm{n}$ years; $\mathrm{r}$ is the discount rate; $R_{\mathrm{M}, \mathrm{i}} 、 R_{\mathrm{I}, \mathrm{i}}$ is the investment and maintenance costs in the implementation of RCE in the $\mathrm{i}$ year of grid enterprises respectively; $R_{\mathrm{L}, \mathrm{i}}$ is the investment cost of HSEB equipment; $R_{\mathrm{A}, \mathrm{i}}$ is the cost of managing HSEB; $R_{\mathrm{E}, \mathrm{i}}$ is the overtime allowance of workers; $\Delta V_{i}$ is the reduction capacity of equipment; $\Delta P_{i}$ is the saving electricity of equipment ; $R_{\mathrm{Q}, \mathrm{i}}$ is the average unit cost of the transmission line of grid enterprises; $\theta_{i}$ is the peak period average price; $\delta_{i}$ is the profit and loss of rotation reserve; $R_{G, S}^{i} 、 R_{G, V}^{i} 、 R_{G, F}^{i}, P_{S}^{i} 、 P_{V}^{i} 、 P_{F}^{i}, T_{S}^{i} 、 T_{V}^{i} 、 T_{F}^{i}$ is the government electricity price subsidies, HSEB power consumption, HSEB time consumption during the peak peroid、 the valley period and the flat period respectively.

\subsection{Benefit model of grid enterprise.}

Grid enterprises' cost of implementing RCE included marketing costs, investment and operation and maintenance costs. Benefits include the benefit of equipment's capacity cuts, the benefit of equipment's saving energy and the benefit of system reliability [6].

The benefit model of power grid enterprise is:

$$
M_{\text {grid }}=\sum_{i=1}^{n} \frac{1}{(1+r)^{i}}\left(R_{M, i}+R_{I, i}+R_{O, i}\right)-\sum_{i=1}^{n} \frac{1}{(1+r)^{i}}\left(\Delta V_{i} R_{G, S}^{i}+\Delta P_{i} \theta_{i}+\delta_{i}\right) \text {. }
$$

Where: $M_{\text {grid }}$ is the power grid enterprise's overall benefit of implementing RCE for n years; $R_{\mathrm{O}, \mathrm{i}}$ is the power grid enterprises' electricity subsidy expenditure of implementing RCE in the i year; $R_{G, S}^{i}$ is the average price duiring peak period.

\subsection{Benefit model of Heating enterprise.}

In the implementation process of RCE, heating enterprises will become the ultimate beneficiaries. In addition, HSEB can also use the valley electricity for boiler' thermal storage. Compared to the coal-fired heating, the cost of HSEB will be relatively low.

The benefit model of Heating enterprise is:

$$
\begin{aligned}
& M_{\text {user }}=\sum_{i=1}^{n} \frac{1}{(1+r)^{i}}\left(R_{L, i}+R_{A, i}+R_{E, i}\right)-\sum_{i=1}^{n} \frac{1}{(1+r)^{i}} R_{O, i} . \\
& R_{W, i}=\sum_{i=1}^{n}\left(P_{S}^{i} \cdot R_{W, S}^{i} T_{S}^{i}+P_{V}^{i} \cdot R_{W, V}^{i} T_{V}^{i}+P_{F}^{i} \cdot R_{W, F}^{i} T_{F}^{i}\right) .
\end{aligned}
$$

Where: $M_{\text {power }}$ is the Heating enterprise's overall benefit of implementing RCE for n years; $R_{W, s}^{i}$ 、 $R_{W, V}^{i} 、 R_{W, F}^{i}$ is the electricity price during the peak peroid 、 the valley period and the flat period respectively.

\subsection{Comprehensive benefit model.}

Through the above analysis, it can draw the conclusion that when the participates' profit of the heating system achieved the maximum value, the corresponding price should be the critical price. The comprehensive benefit model is:

$$
\left\{\begin{array}{c}
F=\max \left(M_{\text {gov }}+M_{\text {grid }}+M_{\text {user }}\right) \\
\text { s.t. } 0 \leq R \leq R_{W, F} \\
P_{V} T_{V} \leq P_{S} T_{S}
\end{array} .\right.
$$


Where: $R$ is critical electricty price. In order to make the technology of RCE get better promotation, the critical electricty price should be less than the electricity price in peak time; $P_{V} T_{V} \leq P_{S} T_{S}$ means that in order to make the HSEB be more economical, the flat time of the operation of the electric boiler should be higher than the peak time.

\section{The analysis of an example}

This paper selected a boiler plant which needs to supply heating to a large park as the research object. Its peak load for the winter is $33600 \mathrm{~kW}$. The investment of purchasing HSEB is about 5620000 yuan, workers' overtime cost is about 150 yuan/h, the equipment's economic operation cycle is 15 years, and the discount rate is $10 \%$. In order to ensure its reliability, the grid enterprise constructed a number of power supply facilities. And grid enterprise's total cost of investment is 4080000yuan, marketing costs 1250000 yuan, the cost of electricity subsidies is 3570000 yuan. The benefit of the equipment's capacity cuts is 32 yuan $/ \mathrm{kW}$, the benefit equipment's saving energy is 0.52 yuan $/ \mathrm{kWh}$, the average price of peak period is 0.79 yuan / $\mathrm{kWh}$.

Select the typical daily load of the region, and the load data are shown in Table 1.

Table 1 Typical daily heating load data sheet the unit of load is million $\mathrm{kW}$

\begin{tabular}{cccccccc}
\hline Time & Load & Time & Load & Time & Load & Time & Load \\
\hline 1 & 2.96 & 7 & 2.97 & 13 & 3.18 & 19 & 3.29 \\
2 & 2.92 & 8 & 3.09 & 14 & 3.32 & 20 & 3.31 \\
3 & 2.90 & 9 & 3.14 & 15 & 3.49 & 21 & 3.38 \\
4 & 2.91 & 10 & 3.17 & 16 & 3.54 & 22 & 3.30 \\
5 & 2.82 & 11 & 3.21 & 17 & 3.30 & 23 & 3.25 \\
6 & 2.80 & 12 & 3.22 & 18 & 3.25 & 24 & 3.23 \\
\hline
\end{tabular}

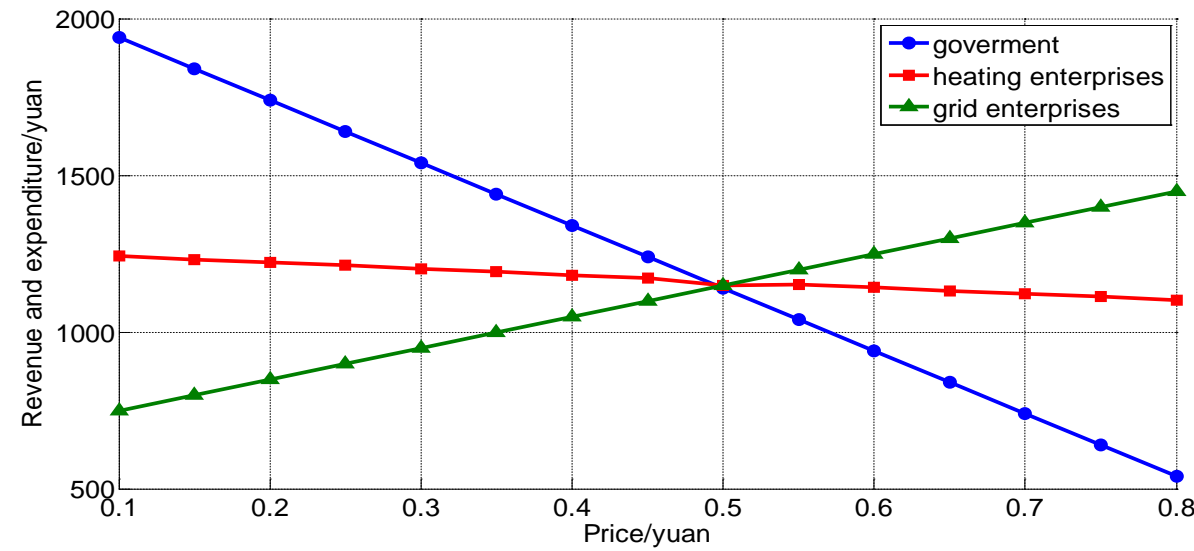

Fig. 1 The curve of the change of revenue and expenditure with the increase of electricity price

Through Fig.1, we knew that with increase of electricity price, power grid enterprise's income gradually increased. Due to an increase in subsidies of users, government's revenue decreased gradually. Users' income have downward trend, but it is not obvious. The intersection point of the curve in Fig. 1 is the maximum point of the participants, so the critical price is $R=0.52 \mathrm{yuan} / \mathrm{kWh}$.

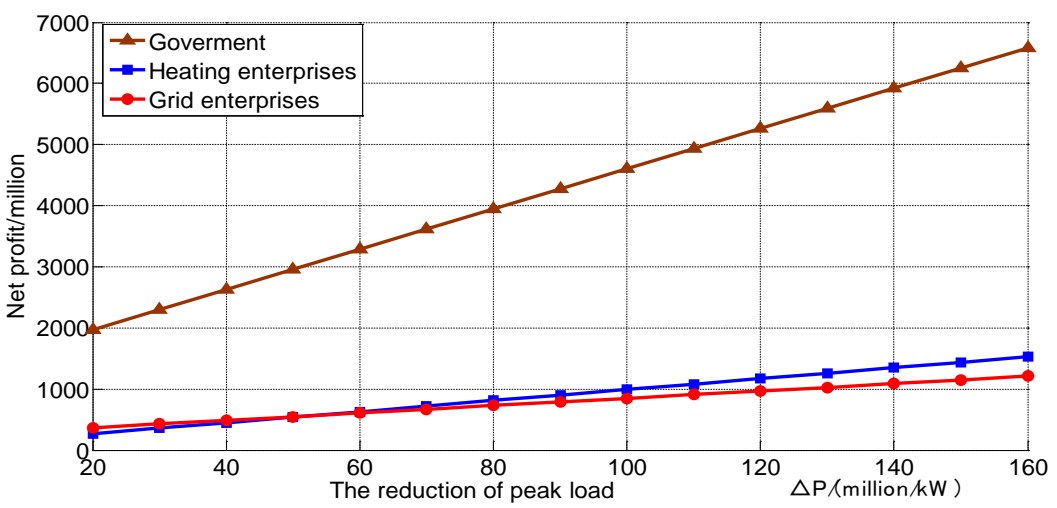

Fig. 2 The curve of the change of net profit with the reduction of the peak load 
Put $R=0.52$ yuan $/ \mathrm{kWh}$ in to the three benefit model, we can calculate the net profit of the main participants of the heating system. In order to verify that the critical price has the function of cutting the peak load, we chose the reduction of peak load as horizontal. The curve of net profit with the decrease of peak load is shown in Fig.1.

Through analysis of above results, we knew that the net profit of government, heating enterprises, and grid enterprises is 4620, 1260, 840 million yuan respectively. The use of critical pricing strategy makes related participates' benefits increase, which is conducive to promotion of EHSB.

In order to verify the effect of reducing system's valley slip by implementing of electric boiler heat storage, this paper did some simulation analysis on the grid. The daily load curves before and after implementing of the electric heat storage boiler are shown in Fig.3.

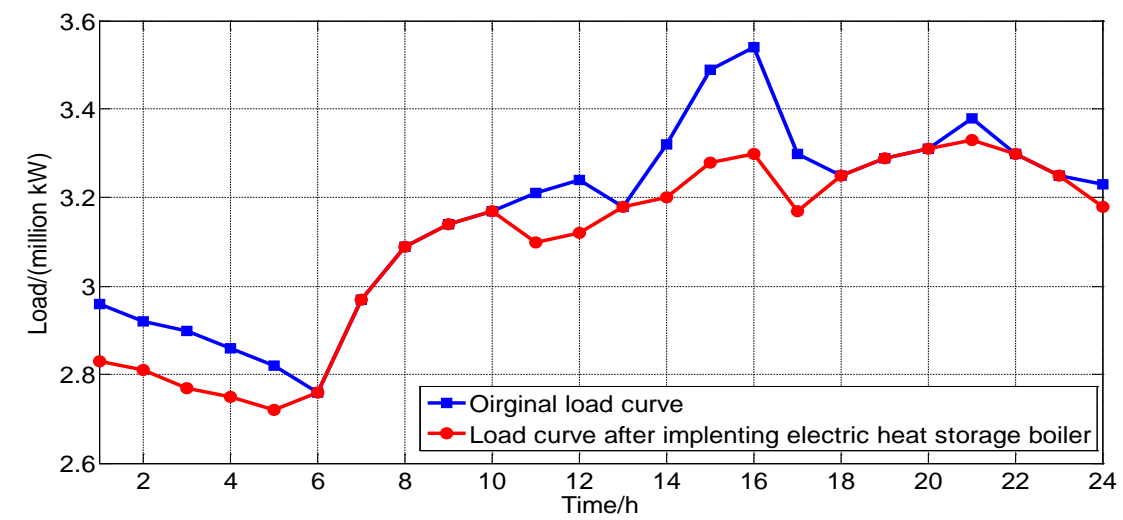

Fig. 3 Load curve before and after implanting electric heat storage boiler

Analyzing the curves in Fig. 3, we knew that the peak load、valley load peak valley ratio of original system and the EHSB system is $3.54 \mathrm{~kW} 、 2.80 \mathrm{~kW} 、 20.9 \%$ and $3.33 \mathrm{~kW} 、 2.75 \mathrm{~kW} 、 17.4 \%$. The peak load's 20\% and 29\% at 11:00 13:00 and14:00 16:00 is transferring to the period of valley, which makes the system run more smoothly and improve the reliability of the system.

\section{Summary}

In the purpose of making electric boiler get better promotion, firstly, this paper analyzed the benefit model of the heating system's subject participating, and introduced the concept of critical price. Secondly, this paper built reasonable benefit model of the participators, and verifies the feasibility of the model through an example.

\section{References}

[1]. X.J. Xu, The design of the heat reservoir heating system of the electric boilers, North China Power Engineering, Beijing , 2006, pp.84-87.

[2]. W.C. Zhang, Application example of water thermal storage by electric boiler, HVAC, 2008, pp. 87-90.

[3]. D. Yu, F. Yang, The study of electric storing heat technique in living hot water system, Contamination Control \& Air-Conditioning Technology, 2009, pp. 19-22.

[4]. X. Zhang, G. Yang, Analysis of the heat reservoir heating water system of the electric boilers program, Refrigeration Technology, 2009, pp. 27.

[5]. Y. Li, K. Xie, Application analysis on electric boiler with thermal technology, Hebei Electric Power, 2009, pp. 31-33.

[6]. Y. Yang, Discussion on the operation of the heating boiler energy conservation problems and countermeasures, The Science of Getting Rich Guide, 2013, pp. 43. 